\title{
Accounting for Steel Stock in Japan
}

\author{
Ichiro DAIGO, Yuma IGARASHI, Yasunari MATSUNO and Yoshihiro ADACHI \\ Department of Material Engineering, Graduate School of Engineering, The University of Tokyo, 7-3-1 Hongo, Bunkyo-ku, Tokyo \\ 113-8656 Japan.
}

(Received on December 22, 2006; accepted on April 19, 2007; originally published in Tetsu-to-Hagané, Vol. 93, 2007, No. 1, pp. 66-70)

\begin{abstract}
During the last two decades, the total material input in Japan has been about 2 billion tons per year, and approximately $50 \%$, i.e., about 1 billion tons, has accumulated as the net addition to stock in the form of buildings, social infrastructure, and various kinds of products. The amount of the net addition to stock is calculated annually from the differential between the input and output. However, the detailed contents of the accumulated stock are unknown. It is said that these unknown contents of stocks include material that has already been discarded as invisible waste. In this study, the following terms are defined: in-use stocks, obsolete stocks, and overall stocks. The materials that are currently used in society are known as "in-use stocks". Obsolete stocks comprise the steels used for the constructional material in a landfill site, the steels dissipated by corrosion and erosion, etc., which are not associated with social activities and cannot possibly be collected as scrap in the future. Overall stocks are the total of these two types of stock. In this study, a dynamic material flow analysis was conducted to quantify the amount of in-use stocks and obsolete stocks. Furthermore, we defined a system boundary to account for the steel stocks and constructed equations to calculate the three types of stock. The amounts of in-use stock and obsolete stock in Japan from 1980 to 2000 were calculated. The result shows that 0.94 billion tons of the in-use stock is included in the 1.22 billion tons of overall stock in the year 2000 .
\end{abstract}

KEY WORDS: in-use stocks; obsolete stocks; material stock accounting; dynamic material flow analysis; societal stock.

\section{Introduction}

In the last two decades, approximately 2 billion tons of natural resources, originating within and outside the country, have been input into Japanese society annually. Each year, approximately half of this amount-about 1 billion tons-accumulates as a net addition to stocks, resulting in a continual increase in the quantity of material in society. ${ }^{1)}$ However, the net addition to stocks is simply calculated by the difference between the material input and output. For this reason, the detailed components of these material stocks in society are unknown. It is thought that this net addition to stocks includes not only products in use but also an unrecognized flow of discarded materials. Brunner $\left.{ }^{2}\right)$ pointed out that the material stocks include obsolete stocks that are no longer of any effective use. Hashimoto et al. ${ }^{3)}$ showed that there are obsolete stocks that are not accounted for from the material balances of construction materials in Japan. Taking steel as an example, these might include an infrastructure such as tunnels and fences, which remain after its useful lifetime has expired, materials that dissipate due to corrosion and abrasion, and materials that remain underground. Such obsolete stocks are not material stocks that contribute to human activities, and there is no possibility that such materials can be recovered as future scrap. By analyzing and classifying the material stocks, a more effective utilization of resources can be discussed by taking into account obsolete stocks such as dissipated materials and underground residual materials.

In recent years, many researches have been done on the recycling of materials using techniques such as the material flow analysis (MFA) and substance flow analysis (SFA) from the perspectives of the health effects of hazardous materials and of effective resource utilization. ${ }^{4)}$ In relation to the material stocks of steel, the Japan Ferrous Raw Materials Association, an industry body, publishes estimated amounts of the total steel stocks in Japan, derived from statistics. ${ }^{5)}$ Toi and Sato ${ }^{6}$ have forecasted the future total steel stocks in Japan from the data mentioned above. Researches by Toi and Sato, ${ }^{7)}$ Kakudate et al.,${ }^{8)}$ Daigo et al.,${ }^{9), 10)}$ Nakajima et al., ${ }^{11)}$ and Tamaki et al. ${ }^{12,13)}$ have also been done on the material flows of steel in Japan. However, all of these studies deal with total material stocks or material flowsthere have been virtually no studies that consider a breakdown of material stocks.

In this study, the following terms relating to stock are defined: in-use stocks, obsolete stocks, and overall stocks. The aim of this study is to assess the quantity of the three types of stock in Japan.

\section{Definition and Determination of Material Stocks}

2.1. Classification and Definition of Material Stocks

Some terms relating to steel stocks are defined. The 
stocks of steel contained in manufactured products that are currently used in society are known as "in-use stocks" $\left(S_{\text {use }}\right)$. The term "obsolete stocks" $\left(S_{\text {obs }}\right)$ refers to steel that remains after its useful lifetime has expired, such as the steel in disused dams and steel that is disspated in the environment invisibly: for example, materials that dissipate due to abrasion and corrosion, as well as materials that are dumped at landfill sites. The total of these two categories is defined as "overall stocks" $\left(S_{\text {all }}\right)$. However, the boundaries between in-use stocks and obsolete stocks and between flows and stocks can be vague, depending on the forms in which materials exist (or are used). Controversial issues remain about the definition of the system boundaries. The system boundaries set in this study are described in the following section.

General definitions of stock are expressed in the form of equations. The amounts of material stocks at time $\tau$ is calculated as the sum of the values of the annual net change in stocks, $\Delta S(t)$, for each year since the initial year $t_{0}$ (Eq. (1)). The net change in stocks in year $t, \Delta S(t)$, is calculated as the difference between the material input in year $t, F_{\text {in }}(t)$, and the material output in year $t, F_{\text {out }}(t)$ (Eq. (2)). Note that here we use the term "net change in stocks" rather than "net addition to stocks" because of the possibility of a net reduction in stock.

$$
\begin{gathered}
S(\tau)=\sum_{t=t_{0}}^{\tau} \Delta S(t) \\
\Delta S(t)=F_{\text {in }}(t)-F_{\text {out }}(t) .
\end{gathered}
$$

Now the data used in this study were obtained from statistics published in annual reports, as we describe below. For the sake of simplicity in the earlier explanation, we assumed a time scale of observation of one year, but the above definitions can also be applied to time scales other than yearly.

\subsection{System Boundaries of Material Stocks}

The published amount of steel stocks in Japan is the value of the "overall stocks," as defined above. ${ }^{5)}$ This amount is derived from the difference between annual material inputs and outputs. The material inputs consist of domestic steel consumption and indirect steel imports in year $t$. The material outputs consist of the amount of recovered steel scrap (total of collected industrial scrap and obsolete scrap) and indirect steel exports in year $t$. Here, indirect steel exports/imports are the amounts of steel exported/imported in the form of manufactured products. This includes exported/imported parts such as knockdown sets. Note that these amounts are estimated separately, since there are no available material-related statistics for them.

In regard to system boundaries, the definitions of "flows" and "stocks" must be considered at first. Faber et al. ${ }^{14)}$ suggested that any changes over a period of time shorter than the observation period should not be considered as "stocks." Because the time for manufacturing and distribution processes, from the mining of iron ore to the delivery of products to consumers, is shorter than the observation period in this study (one year), these processes are considered as a "flow". Although industrial scrap and indirect ex-

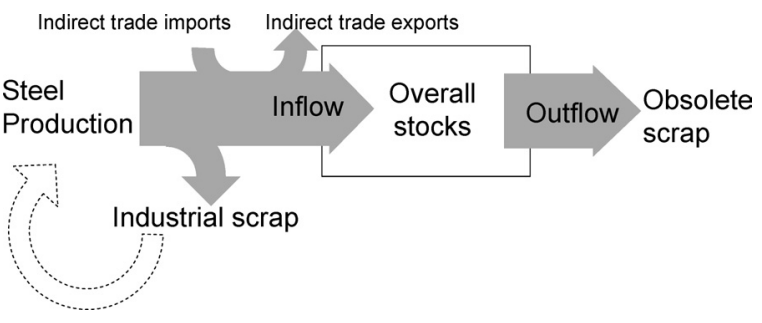

Fig. 1. System boundary of the overall stock of steel in Japan.

ports/imports are considered as material inputs and material outputs in the calculation method described above, they can be regarded as flows outside the system boundary. Therefore, steel materials included in final products that are consumed domestically are considered as material inputs, and the obsolete scrap is as a material output (Fig. 1). The solid line in Fig. 1 shows the system boundary, and steel being in the boundary is calculated as the overall stocks. Note that the products that have shorter lifetime than the observation period of one year should be treated as flows, as was decided for the classification of flows and stocks described above. However, separation of these products from inputs and outputs is not practical for deriving material stocks. In this study, the amount of the short lifetime products is counted as a material input once, and is also counted as a material output within the same period.

\subsection{Derivation Method for Material Stocks}

The derivation method for overall stocks was described in the section on system boundaries. On the other hand, inuse stocks are estimated by taking the domestic steel demand in year $t$ as the material input, and the amount of "disused steel" generated in year $t$ as the material output. Here, "disused steel" is estimated using a dynamic model. The derived amount of "disused steel" is the steel included in products that are disused and are expected to make no further contribution to human activities. The amount of disused steel is estimated using a dynamic model that takes into account the usage period (lifetime) of final products containing steel. A dynamic model in material flow analysis is sometimes referred to as a delay model, ${ }^{15}$ ) in which stocks play the role of time buffers and inputs turn into outputs after a certain time. ${ }^{16)}$ The dynamic analysis technique used in this study is a population balance model ${ }^{8,17)}$; it calculates the amount of disused steel, $F_{\text {out }}$, from the domestic demand, $F_{\text {in }}$, since the start of the period in question, and also the lifetime distribution for each end use category. The demand in year $t$ for a particular end use $i$ is $F_{\text {in }}(i, t)$, and the lifetime distribution of that particular end use is $G(i, \alpha)$ as a cumulative distribution function for the lifetime $\alpha$. Using these quantities, the amount of disused steel for this particular end use $i, F_{\text {out }}(i, t)$ is given by Eq. (3). As also shown by Eq. (4), the total amount of disused steel for all end uses corresponds to the material output for year $t$, $F_{\text {out }}(t)$.

$$
\begin{array}{r}
F_{\text {out }}(i, t)=\sum_{\alpha=0}^{\infty} F_{\text {in }}(i, t-\alpha) \cdot\{G(i, \alpha-1)-G(i, \alpha)\} . . \\
F_{\text {out }}(t)=\sum_{i} F_{\text {out }}(i, t)
\end{array}
$$




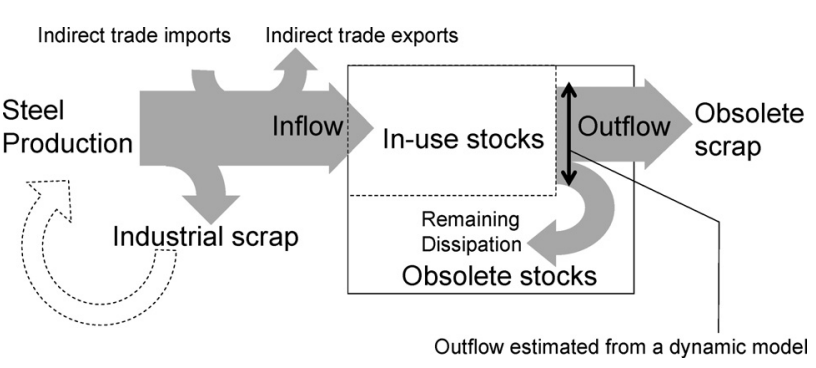

Fig. 2. System boundary of the in-use stock and obsolete stock of steel in Japan.

Note that the input for in-use stocks is the same as the domestic demand for overall stocks; the steel included final products that are consumed domestically.

Looking at the lifecycle of steel in final products, steel is included in the final product and input to society (overall stocks) to become in-use stocks. Then, at the end of the lifetime of the final products, the steel is output from in-use stocks as disused steel. Some of this steel is output from society (overall stocks) temporarily as scrap, while the rest remains in society as obsolete stocks. That is, a portion of the materials that are counted as existing material stocks in overall stocks is treated as discarded materials in in-use stocks. This difference is input to obsolete stocks that can never be recovered as scrap in the future, and so it remains as a part of the material stocks that exist in society. The system boundaries of in-use stocks and obsolete stocks are shown by the dashed and solid lines in Fig. 2, respectively. Note that, for convenience in this study, we express the area within the system boundary of overall stocks as society, although there is still debate on the definition of the terms "society", "anthroposphere", and "technosphere".

\section{Data Collection}

\subsection{Material Input Data}

The domestic demand of materials is generally obtained from statistics. However, the material inputs through system boundaries in this study need to be determined as the quantity of input to society as final products, rather than as the sales volume of material manufacturers or the purchase volumes of final product manufacturers. It is also necessary to consider the process yield in the manufacturing of final products. The amounts of steel products input to society as products in Japan can be estimated ${ }^{5)}$ from domestic demand ${ }^{18)}$ and surveys of the scrap generated by manufacturing. ${ }^{19)}$ Thus, in this study the amounts of steel input to society between 1920 and 2003 was obtained from statistics on the domestic demand for steel and the results of surveys on scrap generated by manufacturing. Note that after 1971, data on the domestic demand quantity by end use is also available, while for the period before 1971 the demand by end use was estimated from the crude steel production for each year, using the ratio of crude steel production to domestic demand by end use for 1971. Furthermore, the crude steel production before 1944 was estimated by extrapolating a function that fits crude steel production between 1945 and 1971 to an exponential function. The crude steel production in tons for year $t$ (in Gregorian years) is expressed by the fitting function $14750 \cdot e^{0.1669} \cdot(t-1920)$. The indirect
Table 1. Category of end-use and corresponding categories in the statistics.

\begin{tabular}{|l|l|}
\hline End-use & Corresponding categories in the statistics \\
\hline Infrastructure & Infrastructure and Other construction \\
\hline Buildings & Buildings \\
\hline Passenger vehicles & Automobiles \\
\hline Trucks & Automobiles \\
\hline Machines & $\begin{array}{l}\text { Industrial machinery, Electrical machine, Household and } \\
\text { commercial equipment, Boats and ships, Railroad vehicles, and } \\
\text { Other transport machinery }\end{array}$ \\
\hline Containers & Containers \\
\hline Other products & Other goods, For next processes, and Unknown \\
\hline
\end{tabular}

exports/imports up to 1993 are taken from data ${ }^{20)}$ published by the World International Iron and Steel Institute, and from 1994 they are taken from data ${ }^{21)}$ estimated by the Japan Ferrous Raw Materials Association.

\subsection{Output Data}

Statistical data on scrap is assessed as the consumption of domestic scrap and the amounts of scrap exports and imports. ${ }^{22)}$ In addition, the amount of industrial scrap is determined using the method described in the previous section. Here, we estimate the amount of collected domestic scrap by subtracting the amount of scrap imports from domestic scrap consumption, and adding the amount of scrap exports to domestic scrap consumption. Furthermore, since all generated industrial scrap is collected, we took the amount of generated industrial scrap to be equal to the amount of collected industrial scrap. Finally, we determined the amount of collected obsolete scrap by subtracting the amount of collected industrial scrap from the amount of collected domestic scrap.

\subsection{Data Used for Dynamic Analysis}

In this study, dynamic approach was applied because steel contained in final products is disused depending on the lifetime of the products in which it is contained. However, it is difficult to accurately determine the lifetime of many products. The finial products were classified into end use category, and a lifetime distribution for each end use category was determined.

From statistical classifications, data on domestic steel demand is available for 15 classes of end use. ${ }^{18)}$ In this study, these 15 classes were integrated and divided into 7 end use categories for our purposes, as shown in Table 1. The "infrastructure" and "other construction" statistical classes were combined to form our "infrastructure" category. Our "buildings" category corresponds to the statistical class "buildings". Our categories "passenger vehicles" and "trucks" were obtained by subdividing the "automobiles" class used in the statistics; these figures were calculated from data on new vehicle registrations for both trucks and passenger vehicles, ${ }^{24)}$ assuming a weight ratio of $2: 1$ between the two. ${ }^{23)}$ Our "machines" category was derived by integrating the statistics classes of "industrial machinery", "electrical machines", "household and commercial equipment", "boats and ships", "railroad vehicles", and "other transport machinery". Our "containers" category corresponds to the "containers" class in the statistics. Our "other 
products" category was obtained by integrating the classes of "other goods", "for next processes", and "unknown". The statistics class "for dealers" represents the demand ${ }^{5)}$ for intermediate transactions among the coil center industry and the sharing and slitting industry. The data ${ }^{25)}$ of "for dealer" categorized by end use was obtained by using annual end use surveys conducted by each industry group.

Next, the product lifetime distribution by end use was prepared as followings. For passenger vehicle and truck end uses, non-parametric lifetime distributions were obtained from statistics ${ }^{24)}$ on the usage of these vehicle classes.

For the lifetime distribution of end uses for which nonparametric lifetime distributions could not be obtained, the Weibull distribution function was used for the distribution function, expressed in Eq. (5) as a cumulative distribution function.

$$
G(x ; m, \eta, \delta)=1-\exp \left(-\frac{(x-\delta)^{m}}{\eta^{m}}\right)
$$

Where $m$ is the shape parameter, $\eta$ is the scale parameter, and $\delta$ is the location parameter of the distribution.

The lifetime distribution for the "infrastructure" end use was determined using the shape parameter $m$ for steel frame buildings, obtained from a previous study. ${ }^{26)}$ The average lifetime of that was assumed that $95 \%$ of constructions are discarded after 60 years - the expected service lifetime of most constructions, as obtained from a reference. ${ }^{27)}$ The product lifetime distribution of the end use "buildings" was evaluated using the lifetime distribution for steel frame buildings obtained from a previous study. ${ }^{26)}$ The lifetime distribution for "machines" utilized the average lifetime ${ }^{7)}$ and the shape parameter ${ }^{28)}$ obtained from previous studies. The lifetime of "containers" is shorter than the observation period of one year, so any lifetime distribution function was not applied. The product lifetime distribution of "other products" was assumed to be the same as that for "machines," considering that "machines" include "other products" as components such as springs and screws. Table 2 shows the prepared lifetime distributions. Note that, as in previous studies, ${ }^{29,30)}$ the validity of the above parameters was confirmed by a comparison between the quantities of collected obsolete scrap obtained by statistics and obtained by the dynamic analysis for data between 1990 and 2000. In the verification, certain collection rates were assumed.

\section{Steel Stocks in Japan}

Using the method described in Sec. 2 and the data described in Sec. 3, overall stocks and in-use stocks were calculated for steel in Japan. Overall stocks are the total of inuse stocks and obsolete stocks, and Fig. 3 shows the results of calculations of in-use stocks and obsolete stocks as a summation graph. In-use stocks and obsolete stocks both exhibit monotonic increases. By definition, obsolete stocks never decrease - they will continue increasing into the future. It is also clear that obsolete stocks make up an increasing proportion of overall stocks over the years. Steel stocks are reported to amount to some 1.2 billion tons in 2000 . Around 0.9 billion tons are estimated to be in-use stocks, while around 1.2 billion tons are counted as overall stocks.
Table 2. Lifetime distribution by each application.

\begin{tabular}{|l|l|l|l|}
\hline End-use & Average lifetime [year] & $\begin{array}{l}\text { Parameters of Weibull } \\
\text { distribution functions }\end{array}$ & References \\
\hline \hline Infrastructure & 34.5 & $\mathrm{~m}=3.1, \quad \eta=48.4, \quad \delta=8.8$ & 26,27 \\
\hline Buildings & 28.9 & $\mathrm{~m}=3.1, \quad \eta=40.4, \quad \delta=7.3$ & 26 \\
\hline Passenger vehicles & $8.7-10.8$ (Across the age) & Non-parametric & 24 \\
\hline Trucks & $8.5-14.1$ (Across the age) & Non-parametric & 24 \\
\hline Machines & 12.1 & $\mathrm{~m}=3.5, \quad \eta=13.4, \quad \delta=0$ & 8,28 \\
\hline Containers & $<1$ & - & - \\
\hline Other products & 12.1 & $\mathrm{~m}=3.5, \eta=13.4, \quad \delta=0$ & 8,28 \\
\hline
\end{tabular}

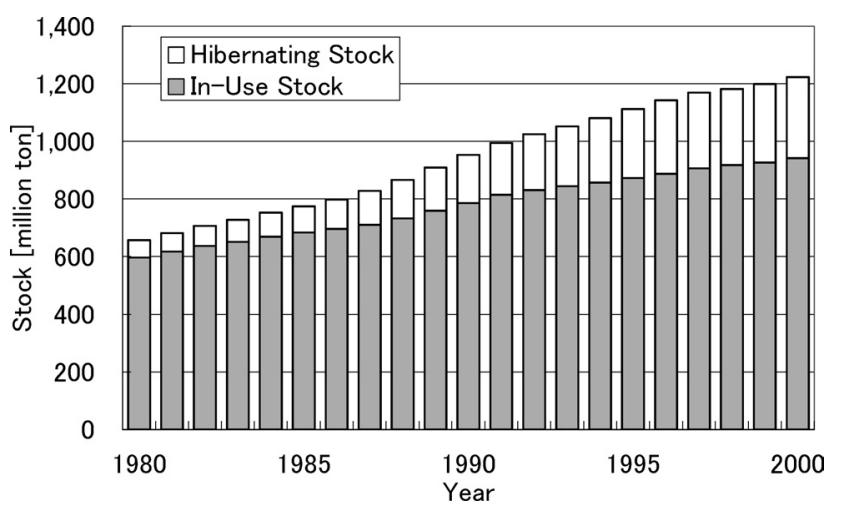

Fig. 3. Steel stock in Japan subdivided into in-use stock and obsolete stock from 1980 to 2000 .

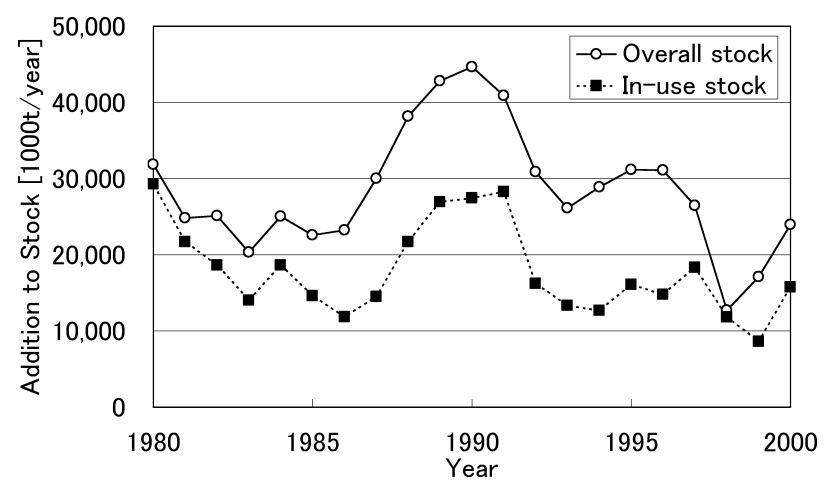

Fig. 4. Change in annual addition to stock from 1980 to 2000.

Figure 4 shows the results of calculations of the net change in stocks for overall stocks and in-use stocks. This figure shows that in the 20 years between 1980 and 2000, the net change in overall stocks was generally about 20 to 30 million tons per year, except for a peak around 1990 and a dip around 1998. In the two decades, the net change in overall stocks gradually declined, except for the peak of 1990. Also, in the first half of the 1980s the difference between the net changes in overall stocks and in-use stocks was relatively small, but this difference increased over the years. The difference between these two net changes represents an increase in obsolete stocks, showing that since the late 1980s obsolete stocks have been growing at a rate of approximately 10 million tons per year.

Furthermore, by subdividing past steel stocks (overall stocks) into the categories of in-use stocks and obsolete stocks in this study, new useful information could be obtained to enable estimation of the future steel demand and scrap collection volumes. However, the figures obtained from the study are strongly influenced by the product life- 
time distributions used to calculate in-use stocks, so further research is needed to enable more accurate determination of these parameters.

\section{Conclusion}

In this study a method for estimating steel stocks was established. Terms for the purpose of breaking down material stocks into categories were defined, with a goal of enabling more effective utilization of resources. We not only calculated the total of existing steel stocks (overall stocks), but also broke these stocks down into the categories of in-use stocks and obsolete stocks. Each of these quantities in Japan was estimated up to the year 2000. It was found that of the total of 1.2 billion tons of overall stocks in 2000 , some 0.9 billions tons were in-use stocks. Further research is required to enable more accurate determination of the parameters used in this study, but we believe that the results are useful knowledge for estimating future steel demand and scrap collection volumes.

\section{Acknowledgements}

In the course of this research, we received valuable advice and information from Mr. Seiichi Hayashi of the Japan Ferrous Raw Materials Association, and Ms. Wakana Tamaki of the Japan Technical Information Service Corporation. We are very grateful for their contributions. This research was supported by a Waste Management Research Grant from the Ministry of the Environment, Japan; K1810 "Development of material stock account framework and its application: strategies for waste/resource management".

\section{REFERENCES}

1) Ministry of the Environment: private communication.

2) P. H. Brunner: Environ. Sci. Pollut. Res., 6 (1999), 1.

3) S. Hashimoto, H. Tanikawa and Y. Moriguchi: Proc. of the 31st Conf. on Environment Systems, Japan Society of Civil Engineers, Tokyo, (2003), 497.

4) P. H. Brunner and H. Rechberger: Practical Handbook of Material Flow Analysis, Advanced Methods in Resource and Waste Management Series,M1, Lewis Pub., Boca Raton, (2003).

5) Year Book of Ferrous Raw Material Statistic 2005, The Japan Ferrous Raw Materials Association, Tokyo, (2006), 55, 68, 89.
6) A. Toi and J. Sato: Tetsu-to-Hagané, 84 (1998), 534.

7) A. Toi and J. Sato: Energy Resour., 18 (1997), 271.

8) K. Kakudate, M. Kawamura, Y. Adachi and T. Suzuki: Tetsu-toHagané, 86 (2000), 425.

9) I. Daigo, Y. Matsuno, K. N. Ishihara and Y. Adachi: Tetsu-toHagané, 91 (2005), 159.

10) I. Daigo, Y. Matsuno and Y. Adachi: Tetsu-to-Hagané, 91 (2005), 171.

11) K. Nakajima, W. Tamaki, D. Fujimaki and I. Daigo: Tetsu-toHagané, 91 (2005), 150.

12) W. Tamaki, Y. Igarashi, D. Fujimaki, S. Hayashi, Y. Tomota, Y. Matsuno and T. Nagasaka: Tetsu-to-Hagané, 92 (2006), 40.

13) W. Tamaki, Y. Igarashi, D. Fujimaki, S. Hayashi, Y. Tomota, Y. Matsuno and T. Nagasaka: Tetsu-to-Hagané, 92 (2006), 46.

14) M. Faber, K. Frank, B. Klauer, R. Manstetten, J. Schiller and C. Wissel: Ecol. Econ., 55 (2005), 155.

15) E. van der Voet, R. Kleijn, R. Huele, M. Ishikawa and E. Verkuijlen: Ecol. Econ., 41 (2002), 223.

16) R. Kleijn, R. Huele and E. van der Voet: Ecol. Econ., 32 (2000), 241.

17) K. Yokota, Y. Matsuno, M. Yamashita and Y. Adachi: Int. J. LCA, 8 (2003), 129.

18) Handbook for Iron and Steel Statistics (1971-2003), Committee on Iron and Steel Statistics, The Japan Iron and Steel Federation (JISF), Tokyo, 1971-2003

19) S. Hayashi and W. Tamaki: Tetsu-to-Hagané, 91 (2005), 167.

20) Commission on Economic Studies, Indirect Trade in Steel1962-1993, International Iron and Steel Institute, Brussels, (1982-1996).

21) Quarterly Ferrous Raw Material Statistics/Monthly Ferrous Raw Material Statistics, The Japan Ferrous Raw Materials Association, (1988-2002).

22) Ministry of Economics, Trade and Industry, Yearbook of Iron and Steel, Non-ferrous Metal, and Fabricated Metals Statistics, Economy, Trade and Industry Statistics Association, Tokyo, (1976-2001).

23) Automotive Guidebook of Japan 2000-2001, Japan Automobile Manufacturers Association, (2000), 47, 221.

24) Road Transport Bureau Ministry of Land Infrastructure and Transport: Jidosha Hoyu Sharyosu 1-31, Automobile Inspection \& Registration Association, Tokyo, (1958-2001).

25) Japan Technical Information Service: private communication.

26) Y. Komatsu, H. Kato, T. Yoshida and T. Yashiro: Archit. Plann. Environ. Eng. AIJ, 439 (1992), 101.

27) Ministry of Land Infrastructure and Transport: White Paper on Land Infrastructure and Transport 2006, Gyosei, Tokyo, (2006).

28) T. Tasaki, M. Oguchi, T. Kameya and K. Urano: J. Jpn Soc. Waste Manag. Experts, 12 (2001), 49.

29) I. Daigo, Y. Matsuno and Y. Adachi: J. Jpn. Inst. Met., 70 (2006), 114.

30) D. Fujimaki, Y. Igarashi, I. Daigo, Y. Matsuno and Y. Adachi: Tetsuto-Hagané, 92 (2006), 45. 